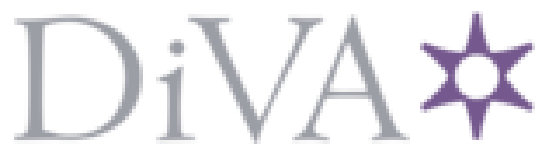

http://www.diva-portal.org

This is the published version of a paper published in Design Issues.

Citation for the original published paper (version of record):

Thornquist, C. (2017)

Unemotional Design: An Alternative Approach to Sustainable Design

Design Issues, 33(4): 83-91

https://doi.org/10.1162/DESI_a_00463

Access to the published version may require subscription.

N.B. When citing this work, cite the original published paper.

Permanent link to this version:

http://urn.kb.se/resolve?urn=urn:nbn:se:hb:diva-15702 


\section{Unemotional Design: An Alternative Approach to Sustainable Design Clemens Thornquist}

1 Deana McDonagh, Paul Hekkert, Jeroen van Erp, and Diane Gyi (eds.), Design and Emotion: The Experience of Everyday Things (London: Taylor \& Francis, 2003); Amic G. Ho and Kin Wai Michael Sue, "Explore the Role of Emotion in Design," Design Principles and Practices: An International Journal 5, no. 3 (2011): 367-78.

2 Donald Norman, Emotional Design: Why We Love (or Hate) Everyday Things (New York: Basic Books, 2004); Trevor van Gorp and Edie Adams, Design for Emotion (Waltham, MA: Morgan Kaufmann, 2012).

3 Helga Dittmar, Karen Long, and Rod Bond, "When a Better Self Is Only a Button Click Away: Associations Between Materialistic Values, Emotional and Identity-Related Buying Motives, and Compulsive Buying Tendency Online," Journal of Social and Clinical Psychology 26, no. 3 (2007): 334-61.

4 Jonathan Chapman, Emotionally Durable Design: Objects, Experiences and Empathy (London: Earthscan, 2005).

5 Valentina Rognoli and Elvin Karana, "Toward a New Materials Aesthetic Based on Imperfection and Graceful Aging," in Materials Experience: Fundamentals of Materials and Design, ed. Valentina Rognoli and Elvin Karana (Oxford: Butterworth-Heinemann, 2014), 147-54.

6 Stuart Walker, "The Environment, Product Aesthetics and Surface," Design Issues 11, no. 3 (Autumn 1995): 15-27.

7 Tomás Moldanado, Design, Nature and Revolution (New York: Harper \& Row, 1972); Ezio Manzini, “Design, Environment and Social quality: From 'Existenzminimum' to 'Quality Maximum,'” Design Issues 10, no. 1 (Spring 1994): 37-43; Domus Academy, The Solid Side-Domus Academy (London: Philips Corporate Design, 1995).

8 Norman, Emotional Design

\section{Introduction}

Emotions are central to design, ${ }^{1}$ and both design and emotions are central to conspicuous consumption. ${ }^{2}$ What role do emotions play in sustainable design - especially when acknowledging the significant environmental impact by conspicuous consumption of not only fashion-conditioned products such as clothing and interior objects, but also household electronics?

Designers like Chapman, for example, have focused on emotionally durable design to change the psychological foundation of the person-product relationship to reduce the environmental impact of unsustainable consumption patterns. ${ }^{4}$ By focusing on the consumption of meaning instead of matter, Chapman suggests that designers should emphasize emotionally durable design that builds on an emphatic relationship with things. It means to design, integrate, and develop the intangible and ethereal nature of considerations pertaining to psychological function that gives greater emotional longevity in products. From this perspective, disregarding a product, or waste, is a symptom of expired empathy, a kind of failed relationship that leads to the dumping of one by the other. Along this train of thought, the perception of aging and imperfection, as Rognoli and Karana note, becomes a valuable means of creating unique, personal, and durable products from materials that foster a caring relationship, based on the affinity the user feels for an object. ${ }^{5}$ Similar arguments can be found on a philosophical level where the material experience, ${ }^{6}$ at the center of a new sustainable aesthetic, is argued to influence concrete changes to behavior and ways of living on a societal level. ${ }^{7}$

Most discussions of emotionally durable design focus primarily on the psychological dimensions of use once a product has been acquired. The discussions often neglect a consideration of the emotions that motivate the acquisition of a new product or the replacement of an existing one. That is, what is the role of emotions in the desire to change an existing situation into a different one? From an emotional design perspective, one attempt to answer this question comes from Donald Norman. ${ }^{8}$ While Norman focuses on emotions in the use of design, he recognizes two other categories that relate to the drive and acquisition of new design: the product's 
9 David Aaker, Managing Brand Equity (New York: Free Press, 1991); Jennifer Aaker, "Dimensions of Brand Personality," Journal of Marketing Research 34 , no. 3 (1997): 347-56; Qing Yao, Rong Chen, and Xiaobing $\mathrm{Xu}$, "Consistency Between Consumer Personality and Brand Personality Influences Brand Attachment," Social Behavior and Personality 43, no. 9 (2015): 1419-427.

10 Seung-Hee Lee and Jane E. Workman,

"Compulsive Buying and Branding Phenomena," Journal of Open Innovation: Technology, Market, and Complexity 1 , no. 3 (2015): 1-2; María de la Paz, Toldos-Romero Ma, and Margarita Orozco-Gómez, "Brand Personality and Purchase Intention," European Business Review 27, no. 5 (2015): 462-76.

11 Tom Djajadiningrat, William Gaver, and Joep Frens, "Interaction Relabelling and Extreme Characters: Methods for Exploring Aesthetic Interaction," in Proceedings of DIS2000 (New York: ACM Press, 2000), 66-71.

12 Sharon E. Beatty and Elizabeth Ferrell, "Impulsive Buying: Modeling Its Precursors," Journal of Retailing 74, no. 2 (1998): 169-91; Thomas R. O'Guinn and Ronald J. Faber, "Compulsive Buying: A Phenomenological Exploration," Journal of Consumer Research 16, no. 2 (1989): 147-57.

13 Alain d'Astous, "An Inquiry into the Compulsive Side of 'Normal' Consumers," Journal of Consumer Policy 13, no. 1 (1990): 15-31, 24.

14 Lorrin M. Koran, Ronald J. Faber, Elias Aboujaoude, Michael D. Large, and Richard T. Serpe, "Estimated Prevalence of Compulsive Buying Behavior in the United States," American Journal of Psychiatry 163, no. 10 (2012): 1806-812; Astrid Mueller, James E. Mitchell, Lisa A. Peterson, Ronald J. Faber, Kristine J. Steffen, Ross D. Crosby, and Laurence Claes, "Depression, Materialism, and Excessive Internet Use in Relation to Compulsive Buying," Comprehensive Psychiatry52, no. 4 (2011): 420-24.

15 Jonah Berger and Chip Heath, "Where Consumers Diverge from Others: Identity Signalling and Product Domains," Journal of Consumer Research 34, no. 2 (2007): 121-34.

16 Djajadiningrat et al., "Interaction Relabelling and Extreme Characters," 66. attractiveness and appearance and the product's image. However, being linked to an individual's visceral and vane behaviorsthe image it portrays, the message it tells others about the owner's taste-these categories of design emotions may be problematic for a conspicuous consumption pattern. In fact, these two categories resonate well with emotional attachment in branding, which is often promoted as the personal affinity for a product and the emotional attachment that a customer has to the image and attractiveness of the product. Being a key function in brand management, emotional attachment is typically understood and promoted using analogies of human characteristics and self-consistency, where product relationships based on consumer empathy have been proven to increase consumption. ${ }^{9}$ Moreover, emotional product strategies has been shown to have a significant positive impact on consumers' purchase intention where brand attachment based on empathy and self-consistency have been related to particularly unsustainable consumption patterns, such as compulsive buying behavior. ${ }^{10}$ The purpose of this article is to explore emotional conditions in the drive for and acquisition of new design more closely, rather than looking at emotions in the use of (design) products.

\section{Extreme Character: Generalized Principles}

To explore emotions connected to the drive for and acquisition of new products, I follow an "extreme characters" approach to discover emotional conditions involved in buying products, ${ }^{11}$ but in situations where exaggerated emotional attitudes are involved. Of particular interest are impulsive buying and compulsive buying. ${ }^{12}$ This interest is motivated by earlier studies in which extreme buying behavior has been partially confirmed as "a generalized behavioral trait in the consumer population rather than a distinctive and defining characteristic of a small and highly polarized consumer sub-population." ${ }^{13}$ In addition, compulsive buying is relatively common, and research has shown that the disorder is widespread and increasing in prevalence. ${ }^{14}$ Both impulsive buying and compulsive buying are directly related to excessive buying, in terms of private, public, natural, and social resources. Second, fashion (clothing and accessories) is also of particular interest as clothing is arguably more constantly on display than other designer products and,$^{15}$ therefore, is particularly related to the direct personal approach and image construction. In other words, sociocultural aspects of design can reveal much about a person's hidden character traits as Djajadinigrat et al. explain, "by taking characters that are extremes, character traits can be exposed which, though common, remain hidden because they are antisocial or in conflict with a person's status. ${ }^{16}$ 
17 Dennis W. Rook, "The Buying Impulse," Journal of Consumer Research 14, no. 2 (1987): 189-99, 191

18 Beatty and Ferrell, "Impulsive Buying," 170.

19 Piyush Sharma, Bharadhwaj Sivakumaran, and Roger Marshall, "Impulse Buying and Variety Seeking: A Trait-Correlates Perspective," Journal of Business Research 63, no. 3 (2010): 276-83, 277.

20 Edmund R. Thompson and Gerard P. Prendergast, "The Influence of Trait Affect and the Five-Factor Personality Model on Impulse Buying," Personality and Individual Differences 76 (2015): 216-21.

21 Bas Verplanken and Ayana Sato, "The Psychology of Impulse Buying: An Integrative Self-Regulation Approach," Journal of Consumer Policy 34, no. 2 (2011): 197-210.

22 Aadel A. Darrat, Mahmoud A. Darrat, and Douglas Amyx, "How Impulse Buying Influences Compulsive Buying: The Central Role of Consumer Anxiety and Escapism," Journal of Retailing and Consumer Services 31 (2016): 103-8.

23 Verplanken and Sato, "The Psychology of Impulse Buying," 197.

24 O'Guinn and Faber, "Compulsive Buying," 149.

25 Elif Ergin, "Compulsive Buying Behavior Tendencies: The Case of Turkish Consumers," African Journal of Business Management 4, no. 3 (2010): 333-38; Michael Kyrios, Randy 0. Frost, and Gail Steketee, "Cognitions in Compulsive Buying and Acquisition," Cognitive Therapy and Research 28, no. 2 (2004): 241-58.

26 David H. Silvera, Anne Lavack, and Fredric Kropp, "Impulse Buying: The Role of Affect, Social Influence, and Subjective Wellbeing," Journal of Consumer Marketing 25, no. 1 (2008): 23-33.

27 Wayne DeSarbo and Elizabeth Edwards, "Typologies of Compulsive Buying Behavior: A Constrained Clusterwise Regression Approach," Journal of Consumer Psychology 5, no. 3 (1996): 231-62.

\section{Impulsive and Compulsive Buying in Conspicuous Consumption}

Early on impulse buying was described as an extraordinary and exciting consumer experience: the "sudden, often powerful and persistent urge to buy something immediately." ${ }^{17}$ Later on it was expanded into "a sudden and immediate purchase with no preshopping intentions either to buy the specific product category or to fulfill a specific buying task. The behavior occurs after experiencing an urge to buy and it tends to be spontaneous" and without full consideration of the consequences, and it "does not include the purchase of a simple reminder item, which is an item that is simply out-of-stock at home." ${ }^{\prime 18}$ More recently, impulse buying has been clearly linked to pleasure as, for example, "a sudden, hedonically complex purchase behavior in which the rapidity of the impulse purchase precludes any thoughtful, deliberate consideration of alternative or future implications." ${ }^{19}$

Several studies concluded impulsive buying to be different in kind and qualitatively distinct from compulsive buying, although impulsive buying may lead to and take the form of compulsive buying. Some studies conclude that impulsive buying is a milder form of compulsive buying, where it is the introduction to compulsive buying behavior and follows the same behavioral characteristics. ${ }^{20}$ Also, impulsive buying and compulsive buying are determined by the same factors, such as materialism and identity concerns. ${ }^{21}$ Impulse buying has furthermore been found to increase anxiety in consumers, which is also linked to compulsive buying. ${ }^{22}$ Moreover, impulse buying and compulsive buying are similar in terms of consequences of excessive buying and they "grossly violate the assumptions of homo economicus." ${ }^{23}$

O'Guinn and Faber define compulsive buying as a "chronic, repetitive purchasing that occurs as a response to negative events or feelings," where the alleviation of these negative feelings is the primary motivation for engaging in the behavior. ${ }^{24}$ This form of buying provide the individual with short-term positive rewards but result in long-term negative consequences, and once developed, the individual faces great difficulty in controlling buying even after its detrimental effects are recognized.

Important in several definitions of compulsive buying is that it has been defined as a primary response to negative feelings (or events) that commonly results in an excessive numbers of objects. ${ }^{25}$ This is also similar to impulsive buying, which is argued to function as an escape from negative psychological conditions. ${ }^{26}$ Although there are different degrees of compulsive buying, an important distinction may be in the findings of DeSarbo and Edwards. ${ }^{27}$ They suggest that milder forms of compulsive buying are driven by materialism, whereas more extreme compulsive buying is driven not by the desire to own things but by the process itself. 
28 David W. Krueger, "On Compulsive Shopping and Spending: A Psychodynamic Inquiry," American Journal of Psychotherapy 42, no. 4 (1988): 574-84.

29 Amande Conseur, Jan Hathcote, and Soyoung Kim, "Consumer Masculinity Behavior Among College Students and Its Relationship to Self Esteem and Media Significance," Sex Roles 58 (2008): 549-55.

30 Krueger, "On Compulsive Shopping and Spending," 574.

31 Hye-Jung Park and Leslie Davis Burns, "Fashion Orientation, Credit Card Use, and Compulsive Buying," Journal of Consumer Marketing 22, no. 3 (2005): 13541.

32 O'Guinn and Faber, "Compulsive Buying."

33 d'Astous, "An Inquiry into the Compulsive Side of 'Normal' Consumers."

34 Paul Rose, "Mediators of the Association Between Narcissism and Compulsive Buying: The Roles of Materialism and Impulse Control," Psychology of Addictive Behaviors 21, no. 4 (2007): 576-81.

35 Donald W. Black, "A Review of Compulsive Buying Disorder," World Psychiatry 6, no. 1 (2007): 14-18.

36 Tricia Johnson and Julianne Attmann, "Compulsive Buying in a Product Specific Context: Clothing," Journal of Consumer Research 13, no. 3 (2009): 394-405.
In relation to fashion, Krueger argues that compulsive buyers are likely to be conscious of how they dress and appear, relating to a concern regarding how one is perceived by others, and concludes that compulsive shopping and spending may be a dual attempt to regulate the affect of a fragmented sense of self and restore a self-object equilibrium..$^{28}$ This argument goes hand in hand with the assertion of Conseur and colleagues that self-esteem resulting from satisfaction with appearance is negatively correlated with overall self-esteem..$^{29}$ That is, one's appearance-related self-esteem is in fact an indicator of deeper insecurities and lack of true self-confidence. Compulsive shopping, then, "occurs as a reparative effort for a disrupted self/self-object bond and the resultant experience of emptiness as well as loss of connectedness and boundaries." ${ }^{30}$ Similarly, Park and Burns argue that compulsive buyers are likely to be very fashion-oriented in their buying behavior. The results of their study show that interest in fashion directly influences compulsive buying behavior, and so, for many retailers, fashion-conscious and fashion-oriented shoppers are an important target audience because they rapidly adopt trends and are often the best customers. ${ }^{31}$

$\mathrm{O}^{\prime}$ Guinn and Faber frame compulsive buying within the larger category of compulsive consumption. ${ }^{32}$ Their results show that people who buy compulsively have lower self-esteem and are more prone to fantasy than are average consumers. The primary motivation for these consumers appears to be the psychological benefits that come from the buying process, rather than from the possession of purchased material objects. The consequences of this kind of compulsive buying include anxiety and frustration, the subjective sense of loss of control as well as domestic dissension.

Although low self-esteem and loss of control are often seen as the cause for compulsive buying, other studies moderate this conclusion, declaring it safer to assume that the vast majority of consumers do not perceive a loss of control in their general buying activities and that self-esteem covaries with the generalized urge to buy. ${ }^{33}$ This is also in line with Rose's work, which concludes that unstable self-esteem, such as a narcissistic personality, is a cause for impulsive and compulsive buying. ${ }^{34}$ Nevertheless, people with compulsive buying disorder (CBD) report a preoccupation with shopping, prepurchase tension or anxiety, and a sense of relief following the purchase. CBD is associated with significant psychiatric comorbidity and particularly mood and anxiety disorders, substance use disorders, and other disorders of impulse control. ${ }^{35}$ Analysis shows significant relationships between neuroticism and materialism, neuroticism and compulsive clothing buying, materialism and fashion interest, and fashion interest and compulsive clothing buying. ${ }^{36}$ Put differently, it means that compulsive fashion 
37 Jean Baudrillard, Simulations (New York: Semiotext(e), 1983).

38 Eun Joo Park, Eun Young Kim, and Judith Cardona Forney, "A Structural Model of Fashion-Oriented Impulse Buying Behavior," Journal of Fashion Marketing and Management 10, no. 4 (2006): 433-46.

39 Lee M. Lawrence, Joseph Ciorciari, and Michael Kyrios, "Relationships that Compulsive Buying has with Addiction, Obsessive Compulsiveness, Hoarding, and Depression," Comprehensive Psychiatry 55, no. 5 (2014): 1137-45.

40 Monika A. Bauer, James Wilkie, Jung K. Kim, and Galen V. Bodenhausen, "Cuing Consumerism: Situational Materialism Undermines Personal and Social WellBeing," Psychological Science 23, no. 5 (2012): 517-23.

41 Jon E. Granta, Marc N. Potenzab, Suchitra Krishnan-Sarinb, Dana A. Cavallob, and Rani A. Desaib, "Shopping Problems among High School Students," Comprehensive Psychiatry 52, no. 3 (2011): 24752.

42 Aniko Maraz, Mark D. Griffiths, and Zsolt Demetrovics, "The Prevalence of Compulsive Buying: A Meta-Analysis," Addiction 111, no. 3 (2011): 247-52.

43 Granta et al., "Shopping Problems among High School Students," 247.

44 Heidi Hartston, "The Case for Compulsive Shopping as an Addiction," Journal of Psychoactive Drugs 44, no. 1 (2012): 64-67.

45 Donnalyn Pompper, "Masculinities, the Metrosexual, and Media Images: Across Dimensions of Age and Ethnicity," Sex Roles 63, no. 9 (2010): 682-96.

46 DeSarbo and Edwards, "Typologies of Compulsive Buying Behavior"; Mueller et al., "Depression, Materialism, and Excessive Internet Use."

47 Mueller et al., "Depression, Materialism, and Excessive Internet Use," 420.

48 Rik Pieters, "Bidirectional Dynamics of Materialism and Loneliness: Not Just a Vicious Cycle," Journal of Consumer Research 40, no. 4 (2013): 615-31. buying may result in a schizophrenic self because of the fragmentations in self-representation and the continuous switching of self-images. ${ }^{37}$

Overall, as Park and colleagues conclude, an interest in fashion and experience of positive emotions have positive effects on consumers' fashion-oriented impulse buying behavior; an interest in fashion has the greatest effect, and a hedonic consumption tendency is an important mediator in determining fashion-oriented impulse buying. ${ }^{38}$ Hedonistic/comfort shopping is also a factor that Lawrence et al. identify as the most important predictor of compulsive buying related to depression. ${ }^{39}$ As Bauer and colleagues show, people who were frequently exposed to images of fashion and luxury goods associated with concepts such as buying, status, assets, and so on experienced increases in anxiety and depression. ${ }^{40}$ Consequently, it may not be surprising that problematic shopping habits appear to be fairly common among high school students, as Granta et al. note. Teenagers are perhaps the group most engaged in socially constructing themselves as individuals in relation to the society they are surrounded by. ${ }^{41}$ This resonates well with many studies that have confirmed a negative relationship between compulsive buying and age, where decreases in compulsive buying come with increasing age. ${ }^{42}$ Compulsive buying is also associated with symptoms of depression and a range of potentially addictive and antisocial behaviors, whereby significant distress and diminished behavioral control suggest that excessive shopping may often have significant associated morbidity. ${ }^{43}$ Correspondingly, some studies describe compulsive buyers similar to substance abusers because of the inability to control the buying behavior. ${ }^{44}$ Simply put, research shows an overall anxiety, confusion, and frustration in consumers with regard to the (in)ability to measure up to media-promoted body images. ${ }^{45}$

Some research indicates that materialism and depression jointly influence compulsive buying, which may mean that there are two separate factors governing the behavior. ${ }^{46}$ For example, one studied group was found to be driven mainly by materialism and a desire for objects, whereas a second "was composed of people whose buying was more motivated by internal feelings such as low self-esteem and having a short-term sense of power or control." ${ }^{\prime 47}$ Although it may be possible to make such a distinction in some consumer areas, in the symbolic fashion system these two factors are arguably impossible to separate due to the explicit role of the object as self-constructive. Pieters points directly to materialist shopping as a means of social comparison and more crucially describes this kind of consumption as a "loneliness loop" that makes the consumer less happy and more prone to acquire more things to fill the void. ${ }^{48}$ Materialism and loneliness, Pieters finds, 
49 Bas Verplanken, Astrid G. Herabadi, Judith A. Perry, and David H. Silvera, "Consumer Style and Health: The Role of Impulsive Buying in Unhealthy Eating," Psychology and Health 20, no. 4 (2005): 429-41.

50 Verplanken and Sato, "The Psychology of Impulse Buying," 197.

51 Julie Sneath, Russel Lacey, and Pamela Kennett-Hensel, “Coping with a Natural Disaster: Losses, Emotions, and Impulsive and Compulsive Buying," Marketing Letters 20, no. 1 (2009): 45-60.

52 Richard Elliot, "Addictive Consumption: Function and Fragmentation in Postmodernity," Journal of Consumer Policy 17, no. 2 (1994): 159-79.

53 Darrat et al., "How Impulse Buying Influences Compulsive Buying."

54 Peter Drucker, Management (New York: HarperCollins, 2008).

55 Dana L. Alden, Jan-Benedict Steenkamp, and Rajeev Batra, "Brand Positioning through Advertising in Asia, North America and Europe: The Role of Global Consumer Culture," Journal of Marketing 63, no. 1 (1999): 75-87. are engaged in bidirectional relationships over time where valuing possessions as a happiness remedy or a measure of success increases the sense of loneliness.

The "loneliness loop" also points at the sometimes paradoxical relationship between impulsive buying and compulsive buying in relation to negative and positive emotional conditions. Verplanken et al. explain, whereas impulse buying is often associated with short-term joy and pleasure, it also correlates with longterm negative mood and low self-esteem. ${ }^{49}$ Similarly Verplanken and Sato show how impulsive buying can be understood to be a psychological functioning, particularly a form of self-regulation where "regulatory focus theory is then used to bring the various perspectives together by classifying each as a promotion focus strategy (e.g., seeking pleasure) or a prevention focus strategy (e.g., avoiding feelings of low self-esteem)." ${ }^{50}$ In respect to this, Sneath and colleagues have shown how in the aftermath of a traumatic event, impulsive buying appears to be a rational and beneficial behavior to neutralize negative feelings; for example, disaster victims engage in distinct impulsive purchasing behaviors to manage emotional states, recoup losses, and restore their sense of self. ${ }^{51}$ Elliot has pointed out, ${ }^{52}$ and they show that the relationship between depression and compulsive buying was significantly stronger for lower income individuals and that compulsive buying may be a learned, adaptive behavior.

While Darrat et al. show that impulse buying increases anxiety in consumers and that consumer anxiety in turn plays a key role in the relationship between impulsive and compulsive buying, their study also shows that escapism could buffer the conversion of anxiety into compulsive buying. ${ }^{53}$ Essentially, these consumers cope with negative emotions and apprehension through imagination and fantasizing and thus avoid the trap of addictive buying (coping theory). A possible rationale for this, the same study argues, may be that extreme differences in mood states (positive and negative) are a characteristic of compulsive consumers. It appears, they conclude, that impulsive consumers who experience anxiety are able to stabilize their mood to a more moderate level by engaging in escapism, and as a result of this, they engage in less compulsive buying.

\section{Enabling Emotional Conditions}

While the notions of impulsive buying and compulsive buying behavior present serious concerns about the health of the individual and for the state of culture, economy, and environment at large, they present opportunities for some. Drucker explains: "Social problems are dysfunctions of society and-at least potentially-degenerate diseases of the body politic. They are ills. But 
56 Nasreen Khan, Lai H. Hui, Tan B. Chen, and Hong Y. Hoe, "Impulse Buying Behaviour of Generation Y in Fashion Retail," International Journal of Business and Management 11, no. 1 (2016): 144-51.

57 Aastha Verma Vohra, "Materialism, Impulse Buying and Conspicuous Consumption: A Qualitative Research," Global Business Review 17, no. 1 (2016): 51-67, 64.

58 lan Phau and Charise Woo, "Understanding Compulsive Buying Tendencies among Young Australians," Marketing Intelligence and Planning 26, no. 5 (2008): 441-58.

59 Marta Knas, "The One with a Different View | Meet Ann-Sofie Back," Meet the Designer (2012), http://meetthedesigner. co.uk/2012/11/the-one-with-a-differentview-meet-ann-sofie-back/ (para. 1) (accessed September 7, 2016).

60 Robert J. Donovan, John R. Rossiter, Gilian Marcoolyn, and Andrew Nesdale, "Store Atmosphere and Purchasing Behavior," Journal of Retailing 70, no 3. (1994): 283-94; Monica Kukar-Kinney, Nancy Ridgway, and Kent Monroea, 'The Relationship between Consumers' Tendencies to Buy Compulsively and Their Motivations to Shop and Buy on the Internet," Journal of Retailing 85, no. 3 (2009): 298-307; Mike Featherstone, "Perspectives on Consumer Culture," Sociology 24, no. 1 (1990): 5-22; James A. Roberts and Eli Jones, "Money Attitudes, Credit Card Use, and Compulsive Buying among American College Students," Journal of Consumer Affairs 3, no. 2 (2001): 213-40; Michael Neuner, Gerhard Raab, and Lucia A. Reisch, "Compulsive Buying in Maturing Consumer Societies: An Empirical Re-inquiry," Journal of Economic Psychology 26, no. 4 (2005): 509-22.

61 Yi-Fen Chen and Ruo-Yu Wang, "Are Humans Rational? Exploring Factors Influencing Impulse Buying Intention and Continuous Impulse Buying Intention," Journal of Consumer Behaviour 15, no. 2 (2016): 186-97, 195.

62 Richard Flight, Melissa Rountree, and Sharon Beatty, "Feeling the Urge: Affect in Impulsive and Compulsive Buying," Journal of Marketing Theory and Practice 20, no 4. (2012): 453-66. for the management of institutions and above all, business management, they represent challenges. They are major sources of opportunity." ${ }^{54}$ For example, in relation to the findings by Sneath et al., Alden and colleagues suggest that branding strategies may be more successful in consumer cultures with a lower level of economic development, where the consumers prefer brands out of admiration and on the basis of what higher social status it will confer. ${ }^{55}$

In addition, research findings in impulsive buying and compulsive buying may, for example, enable global marketers to develop an effective market segmentation strategy for compulsive buying behavior, ${ }^{56}$ in which companies create advertising campaigns that portray images of status and prestige to appeal to young adults. Vohra puts it: "Marketing managers should foster on the efforts of media planning because it was found through this study that TV viewing taps into a latent, and apparently, a universal human desire for material enrichment. The habits of consumers are shaped by the intensive exposure to the marketing activities of multinational firms, for example, TV advertisements and magazines; therefore, it is advisable to focus more on the promotion element of the marketing mix." ${ }^{\prime 57}$ This form of promotion is thought to be best paired with aggressive in-store promotion and selling techniques that highlight the discount or best buy slogans. ${ }^{58}$ Such tactics are particularly effective because compulsive buyers are driven by negative emotions, and so, "while 90\% [perhaps] of designers would happily claim their clothes are designed for the confident woman," Ann-Sofie Back happily declares that "she designs for weak people with thick wallets!" ${ }^{\prime 59}$

Although a traditional place for evoking impulsive buying is the physical store, today the easy access provided by online shopping and the loss of financial control mechanisms through credit and credit card practices have also been found to stimulate the continued growth of compulsive buying. ${ }^{60}$ Expressed in more detail, a study with similar findings concludes its implications for managers: "This study indicated that in online promotion situation manipulation, given the same discount amount, consumers experience more impulse stimulus from price reduction promotion than from price discount promotion." ${ }^{61}$ Similarly, the study suggests that online stores should offer a cash refund promotion at the higher threshold to elicit consumers' continuous impulse buying intention, because it is found that cash refund promotion evokes higher impulse buying intention and increases the consumer's intention to continue to buy. Hence, even though the most obvious advice for managers, concluded by Flight et al., ${ }^{62}$ would be to make conscious efforts to stop manipulating environments to trigger impulsive/ compulsive behaviors, this is clearly not the case. 
63 Gerard P. Prendergast, Derek T. Y. Poon, Alex S. L. Tsang, and Ting Yan Fan "Predicting Premium Proneness," Journal of Advertising Research 48, no. 2 (2008): 287-96.

64 Shruti Gupta, "A Literature Review of Compulsive Buying —A Marketing Perspective," Journal of Applied Business and Economics 14, no. 1 (2013): 43-48.

65 Naomi Wolf, The Beauty Myth: How Images of Beauty Are Used against Women (New York: Morrow, 1991).

66 Thomas F. Cash, "Body Image: Past, Present, and Future," Body Image 1, no. 1 (2004): 1-5; Linda Smolak, "Body Image," in Handbook of Girls' and Women's PSychological Health: Gender and WellBeing across the Lifespan, Judith Worell and Carol Goodheart, eds., Oxford Series in Clinical Psychology (New York: Oxford University Press, 2006), 69-76; Viren Swami, David A. Frederick, Toivo Aavik, Lidia Alcalay, Jüri Allik, Donna Anderson, and Ivanka Zivcic-Becirevic, "Body Weight Ideals and Body Dissatisfaction in 26 Countries across 10 World Regions: Results of the International Body Project I," Personality and Social Psychology Bulletin 36, no. 3 (2010): 309-25.

67 James A. Roberts and Cesar M. Sepulveda, "Money Attitudes and Compulsive Buying: An Exploratory Investigation of the Emerging Consumer Culture in Mexico," Journal of International Consumer Marketing 11, no. 4 (1999): 53-74; Astrid Mueller, James E. Mitchell, Christian Mertens, Ulrike Mueller, Andrea Silbermann, Melissa Burgard, and Martina de Zwaan, "Comparison of Treatment Seeking Compulsive Buyers in Germany and the United States," Business Research and Therapy 45, no. 7 (2007): 1629-38.

68 Letty Workman and David Paper, "Compulsive Buying: A Theoretical Framework," Journal of Business Inquiry 9, no. 1 (2010): 89-126.
Looking at the managerial implications in studies like the foregoing, it is obvious that different marketing tactics directly target compulsive buyers-many of which are based on buyer attraction to deals, which temporarily relieve feelings of anxiety, low selfesteem, and stress. ${ }^{63}$ Although several of the researchers who promote the cultivation of compulsive buying through marketing are careful to state that such techniques should be implemented in a socially responsible manner, ${ }^{64}$ since the connection between marketing practices and compulsive buying raises serious ethical issues, such statements seem facetious. According to Wolf, global fashion marketing practices have managed to maintain social control in the form of the beauty myth, an obsession with physical perfection that traps the modern consumer in an endless spiral of hope, self-consciousness, and self-hatred while she tries to fulfill society's impossible definition of "the flawless beauty." ${ }^{\prime 65}$ In other words, in modern consumer societies, individuals are subjected to powerful culturally determined pressures that have resulted in a normative anxiety about negative body image and appearance in a much wider sense. ${ }^{66}$ Similarly, and in line with the foregoing findings, this development of consumer culture has led researchers to conclude that marketing practices have powered a transformation of compulsive consumption into not only common and widespread phenomena but even a normalized behavior and social practice. ${ }^{67}$

\section{Conclusions}

Here I have investigated emotional conditions in buying products for expressive consumption. Of particular interest was exploring the emotional conditions in the buying of design. The results suggest that anxiety has a key function in buying design, especially socially visible products related to an individual's appearance. Anxiety also appears to be a significant link between impulsive and compulsive buying, where impulsive buying is found to increase anxiety in consumers, which is linked to compulsive buying. Moreover, studies indicate that compulsive buying is particularly related to negative mood, where repeated buying of new products provides instances of temporal pleasure. This makes some studies conclude that rather extreme differences in mood states (positive and negative) are a more appropriate characteristic of compulsive consumers than only negative mood. Similarly, while some studies found low appearance-related self-esteem to be a key trait in impulsive and compulsive buying, others conclude that levels of appearance-related self-esteem instead covaries with the generalized urge to buy. In relation to the evidently pathological scores indicated in relation to compulsive buying, expressions like "shopaholic" and "retail therapy" do not seem farfetched" ${ }^{68}$ 
69 Flight et al., "Feeling the Urge."

70 Jonathan Chapman, "Design for (Emotional) Durability," Design Issues 25, no. 4 (Autumn 2009): 29-35, 33.

71 Darrat et al., "How Impulse Buying Influences Compulsive Buying"; Ben Hague, Stephen Kellett, and Paschal Sheeran, "Testing the Generalizability of Impulse Control in Compulsive Buying," Journal of Social and Clinical Psychology 35, no. 4 (2016): 269-88. particularly not when some research describes compulsive buyers similar to substance abusers because of their inability to control their behavior.

Because of a consequence of the principally negative emotional conditions involved in conspicuous consumption of fashionrelated goods, this article suggests an emotional detachment from design for a more sustainable consumer relationship with objects. This conclusion supports earlier findings that the most obvious advice for managers would be to make a conscious effort to stop manipulating environments to trigger impulsive/compulsive behaviors. ${ }^{69}$ Interestingly, this conclusion lines up with a marginalized point in Chapman's work concerning emotions in the use of design. Although emotionally durable design principally encourages emotional attachments in the lived experience of design, Chapman happens to mention, almost incidentally, in a very brief passage that "attachment may actually be counterproductive, as it elevates the level of expectation within the user to a point that is often unattainable." Through emotional detachment, Chapman reasons, the user may have lower expectations and thus perceive the product in a favorable way because of the lack in emotional demand or expectation..$^{70}$ In relation to this, it may be important to note that design for emotional detachment does not mean unempathetic design, since the empathy for products is what is challenged through unemotional design.

From a design perspective, the question that remains is "what general approaches or particular designs can be developed for emotional detachment." More particularly, what unemotional approaches and unemotional designs can be developed for an emotional detachment from fashion-related consumer goods while still acknowledging fundamental expressive cultural values that may be related to aspects of conspicuous consumption? Perhaps, better still, the question may not be so much about the identification of antecedents or the conceptualization of general approaches, as Darrat et al. and Hague et al. argue in the case of compulsive consumption behavior, ${ }^{71}$ but to design and develop practical behavioral remedies that do not only have the potential to reduce consumption but which perhaps have a positive effect on those aspects of quality of life related to mood, anxiety, and self-esteem. 